\title{
Prevalence and Use of Dietary Supplements Among Pharmacy Students in Saudi Arabia
}

This article was published in the following Dove Press journal:

Risk Management and Healthcare Policy

\author{
Sana Samreen (iD) \\ Nasir A Siddiqui ${ }^{2}$ \\ Syed Wajid ${ }^{3}$ \\ Ramzi A Mothana ${ }^{2}{ }^{2}$ \\ Omer M Almarfadi ${ }^{2}$ \\ 'Department of Pharmacy, College of \\ Pharmacy, Aurobindo College of \\ Pharmaceutical Sciences, Warangal, India; \\ ${ }^{2}$ Department of Pharmacognosy, College \\ of Pharmacy, King Saud University, \\ Riyadh, Saudi Arabia; ${ }^{3}$ Department of \\ Clinical Pharmacy, College of Pharmacy, \\ King Saud University, Riyadh, Saudi \\ Arabia
}

Purpose: Dietary supplements (DSs) are popular in many countries, and their use among individuals is increasing worldwide. Therefore, this study aimed to assess the prevalence and use of DSs among pharmacy students in King Saud University College of Pharmacy, Riyadh, Saudi Arabia.

Methods: This study used a cross-sectional design targeting male senior pharmacy students in their fourth and fifth years of Bachelor and Doctor of Pharmacy courses. The data were collected between August and October 2019 using paper-based questionnaires.

Results: A total of $46.8 \%$ of the students used DSs. Of all students surveyed, $19 \%$ used branded supplements whereas $9.7 \%$ used generic or local supplements and $12.3 \%$ used both generic and branded supplements. Furthermore, $8.2 \%$ students suffered from side effects, including 5.6\% who suffered from nausea, vomiting, and diarrhea and $2.6 \%$ who suffered from headache, confusion, and disorientation. Approximately $24.6 \%$ of students used fiber DSs whereas $19 \%$ and $16.4 \%$ used DSs for protein and glucosamine/omega 3 fatty acids, respectively.

Conclusion: The study findings indicated that the prevalence of DS use is increasing. However, approximately half of the respondents encourage the use of DSs only with a doctor's recommendation. Educating about the safe use of DSs is warranted.

Keywords: dietary supplements, performance boosters, pharmacy students, minerals, vitamins, Saudi university

\section{Introduction}

One of the increasing trends in the healthcare industry is the use of dietary supplements (DSs), which significantly playing an increasingly important role in the global economy. ${ }^{1,2}$ The Food and Drug Administration (FDA) has defined DSs as the combination of one or more vitamins, minerals, amino acids, and traditional herbal medicines that is intended to add additional nutritional value to the diet. ${ }^{3}$ The use of DSs has increased and gained more popularity due to their safety and/or effectiveness for helping individuals meet their nutritional goals. $^{4-13}$ Multiple studies have reported the widespread use of DSs among college students including those in Saudi Arabia and other countries. ${ }^{7,14-21}$ According to a recent online survey, approximately $76 \%$ of adults use DSs. ${ }^{22}$ Among DS users, 9 out of 10 were confident about the quality, safety, and effectiveness of DSs. ${ }^{22}$ The literature has reported that the prevalence of DS use is higher among college students compared with other populations. Additionally, previous findings have suggested that weekly use of different types of DSs was high among college students. ${ }^{20}$
Correspondence: Syed Wajid

Tel +966-I I-4677256

Fax +966-II-4677245

Email wali@ksu.edu.sa 
A recent report among undergraduates stated that 52\% of students were using at least one type of DS; ${ }^{7}$ similarly, a study among Nigerian college students reported a DS use prevalence of $86 \%$, with the most common DSs being vitamins. $^{23}$ A nationwide survey of college students aged 18 to 24 years old from Tokyo reported a DS use prevalence of $16.8 \%$, with the primary reasons for using DSs cited as building muscle to improve looks and to lose weight. $^{24}$

Most previous reports from Arab countries have revealed the increased use and demand for DSs. ${ }^{25,26}$ For example, a recent study among college students in Saudi Arabia revealed a high use $(76.6 \%)$ of DSs. ${ }^{15}$ Similarly, a study among professional athletes reported a very high prevalence of DS use (93\%). ${ }^{27}$ Another study on college students from Qatar reported that $49.6 \%$ of students used DSs. ${ }^{28}$ Similarly, a recent study among medical students from Dammam, Saudi Arabia reported a DS use prevalence of $47 \%{ }^{16}$

Several earlier studies demonstrated that a higher use of DSs was associated with knowledge about supplements and attitudes of individuals. ${ }^{19,29,30}$ However, studies also reported that individuals with higher economic status and healthier lifestyles were more likely to consume DSs. ${ }^{31,32}$ Furthermore, students who did not smoke and were physically active were more likely to consume DSs. ${ }^{31,32}$ The previous literature also highlights that students belonging to health-care disciplines were more likely to consume DSs compared with students in other disciplines. ${ }^{19,20}$

Despite the benefits of DS use, evidence has suggested that there are potential problems. For example, users might see them as a substitute, rather than a supplement, for the intake of healthier food or poor food habits. ${ }^{14,33}$ More importantly, unintentional overdose may result in serious side effects associated with DS use. ${ }^{14-18,34}$ Additionally, studies found that high use of DSs was associated with serious adverse events such as convulsions, unconsciousness, palpitations, blood and hepatic disorders, allergic reaction, and death. ${ }^{35,36}$ Regardless of the popularity of DSs throughout the world, a limited number of studies have been conducted in Saudi Arabia that estimate the prevalence, views, and opinions about DS use among senior pharmacy students. ${ }^{15,17,19}$ Therefore, the present study was conducted to measure the prevalence and use of DSs among pharmacy students at King Saud University, College of Pharmacy, Riyadh, Saudi Arabia.

\section{Materials and Methods}

\section{Study Design and Participants}

This cross-sectional descriptive study was conducted between August and October 2018 among King Saud University Pharmacy Students, Riyadh, Saudi Arabia. Senior students in the fourth and fifth years of their Bachelors (B. Pharmacy degree) and PharmD courses who were currently living on the university campus were included. The data collection was performed using paperbased printed questionnaires and was self-administered. This study was approved by the Institutional Review Board of King Saud University, College of Medicine, Saudi Arabia (E-19-4280). All participants provided their written informed consent to participate in this study.

There were approximately 300 senior residential students from both courses (bachelors and PharmD) at the $\mathrm{KSU}$ campus from whom we could obtain the required sample size as calculated with the Raosoft sample size calculator (http://www.raosoft.com/samplesize.html) with a $95 \%$ confidence level and a pre-determined margin of error of $5 \%$. We assumed that the response distribution for each question would be $50 \%$ because we were unsure of the potential results for each question. The calculated sample size was 169 , but we decided to survey 210 students in an attempt to ensure a higher reliability.

\section{Study Instrument and Data Collection}

A self-administered paper-based questionnaire was collected and prepared from previous literature. ${ }^{15,16,19,27}$ The questionnaires consisted of three parts. The first part evaluated age, faculty type, health condition of the participants, cost of DSs, and residential status. The second part included the use of DSs recently, side effects from DS use, most frequently used DSs, types of DSs used, and opinions regarding DSs. The third part addressed the most common reasons for using DSs among the participants. The prepared questionnaire was reviewed and revised by a panel of experts (two professors and one researcher) who belonged to the College of Pharmacy, Clinical Pharmacy department, to validate the contents. The prepared study questionnaires were translated forward and then backtranslated by a certified Arabic speaker. The reliability was determined from a pilot study conducted among a sample of 10 randomly selected pharmacy students. The Cronbach's alpha coefficient was 0.71 , which indicated that the questionnaire could be used in this study. Data collection was performed using a convenience 
sampling technique. Convenience sampling is a nonprobability sampling technique in which the study subjects are selected based on certain criteria, such as availability at a given time, willingness to participate, easy accessibility, and geographical proximity to the researchers. ${ }^{37}$

In this study, we defined a branded supplement as a pharmaceutical product developed by a pharmaceutical industry that was protected by a patent for a specified period of time by a health regulatory authority. A generic supplement is equivalent to a branded product and has a similar therapeutic effect as the branded product; it is developed after expiration of the patent that was originally granted for the branded product by obtaining legal permission from the regulatory agencies. ${ }^{19}$

The data collection mainly targeted senior students receiving their Bachelors (B. Pharmacy degree) and PharmD at KSU, College of Pharmacy. The participants were approached by the researcher from the College of Pharmacy, Clinical Pharmacy Department for the purpose of data collection. Before distributing the study questionnaire to the subjects, the purpose of the study was clarified, and the researcher explained how to complete the questionnaire. The data were collected by visiting the students during their free times. The participants were asked to complete the consent form and were then directed to complete the questionnaire within 30 minutes while being supervised in our presence.

\section{Data Management}

Data extraction is a crucial step in the research process and involves the careful examination of complete and incomplete questionnaires. ${ }^{38}$ In the current study, data were checked for accuracy and completeness. Missing responses or incomplete responses were excluded from the study, as shown in Figure 1.

\section{Statistical Analysis}

The data were extracted to exclude the bias in the sample selection, which was limited to only senior students, and were analyzed using the Statistical Package for Social Sciences version 22.0 (SPSS Inc., Chicago, IL, USA). Descriptive statistics with numbers and frequencies were used to describe the various study variables. The Chisquare test was utilized to identify associations between the demographic variables and study questions. A $p$ value of $<0.05$ was considered statistically significant.

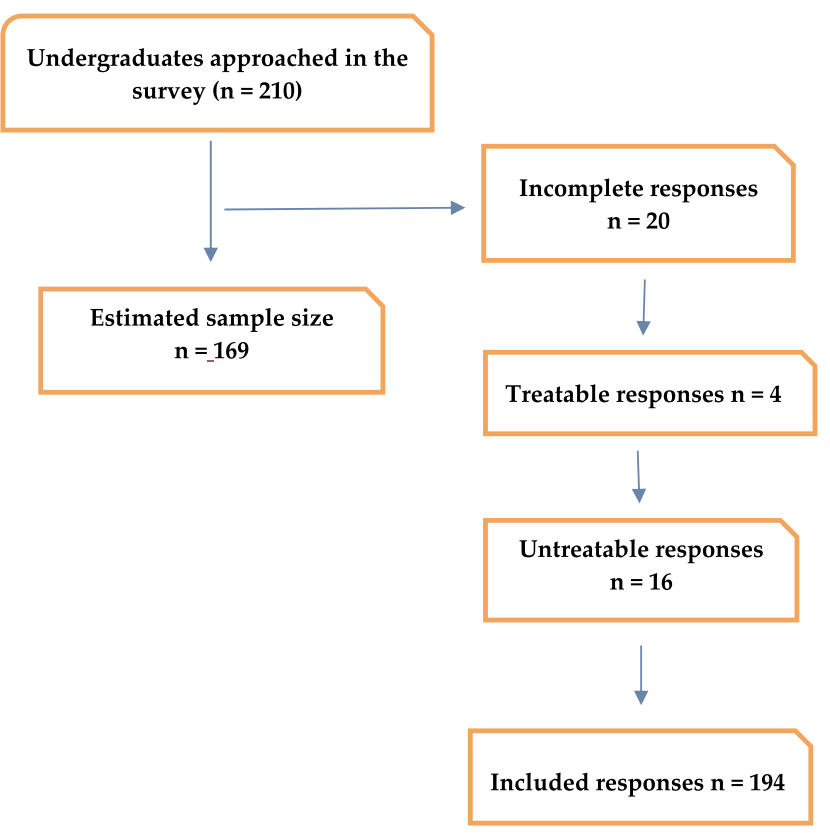

Figure I Flowchart of the responses.

\section{Results}

A total of 210 pharmacy students were approached in this study, and 16 (7.6\%) questionnaires were excluded because of incomplete data. Among the respondents, 194 students completed the questionnaire, corresponding to a response rate of $92.3 \%$. Most of the respondents were PharmD students (55.9\%) and had an average age of 21.4 \pm 1.3 years. Among the 194 students who completed the survey, most $(\mathrm{n}=114,58.5 \%)$ lived with family whereas $11.3 \%$ lived alone. Most of the respondents (89.7\%) did not suffer from any aliments. Detailed information of the demographic characteristics are shown in Table 1.

The study reported a DS use prevalence of nearly $46.8 \%$ among the respondents. Interestingly, slightly less than half $(43.8 \%)$ had never used any DSs recently whereas $9.2 \%$ were unsure about their use of DSs. Among the surveyed students, $19 \%$ used branded supplements, 9.7\% used generic or local supplements, and $12.3 \%$ used both generic and branded supplements. Interestingly, $15.4 \%$ of students were unaware of the type of DSs they used. Approximately $8.2 \%$ of students suffered from side effects related to DS use, including $5.6 \%$ who suffered from gastrointestinal reactions such as nausea, vomiting, and diarrhea and $2.6 \%$ who suffered from headache, confusion, and disorientation. Among DS users, $24.6 \%$ used fiber DSs, followed by $19 \%, 16.4 \%, 11.3 \%$, and $11.3 \%$ who used DSs for whey protein, glucosamine/omega 3 fatty acids, multivitamins (mixture of A-Z), and ginseng, 
Table I Demographic Characteristics of the Respondents

\begin{tabular}{|l|l|l|}
\hline \multicolumn{1}{|l|}{ Study Variables } & $\begin{array}{l}\text { Frequency } \\
\text { (N) }\end{array}$ & $\begin{array}{l}\text { Percentile } \\
\text { (\%) }\end{array}$ \\
\hline $\begin{array}{l}\text { Age (Mean } \pm \text { std) } \\
\text { Cost of the dietary supplement } \\
\text { (Mean } \pm \text { std) }\end{array}$ & $\begin{array}{l}21.48 \pm 1.3 \\
164.2 \pm 122.1\end{array}$ \\
\hline $\begin{array}{l}\text { Year of study at the Faculty of } \\
\text { Pharmacy } \\
\text { Fourth year } \\
\text { Fifth year }\end{array}$ & \multicolumn{2}{|l|}{} \\
\hline $\begin{array}{l}\text { Faculty Type } \\
\text { Doctor of Pharmacy (PharmD) } \\
\text { Bachelors in Pharmacy (B. Pharm) }\end{array}$ & 85 & 58.5 \\
\hline Living status & 80 & 41.4 \\
Living with family & & 55.9 \\
Living alone & 172 & 43.8 \\
\hline Do you suffer from any illness? & & 88.2 \\
Yes & 19 & 11.3 \\
No & 175 & 8.8 \\
\hline
\end{tabular}

Abbreviation: SR, Saudi riyals.

respectively. Detailed descriptions of the responses are shown in Table 2.

Table 3 indicates the attitudes of students toward DS use. Most students (86.7\%) agreed that DSs are good for health while $2.6 \%$ disagreed. However, approximately half $(51.8 \%)$ of the participants stated that they would only encourage the use of DSs upon doctor recommendations whereas $36.4 \%$ would always recommend the use of DSs (see Table 3).

Approximately one-third of the students (35.9\%) agreed that DSs were necessary for all age groups. Although $25.1 \%$ of the students agreed that regular DS use prevents chronic diseases, $4.1 \%$ thought that DSs may prevent cancer. Figure 2 indicates the students' views regarding DSs.

The most common reasons for using DSs were general health and wellbeing $(\mathrm{n}=51,26.2 \%)$, followed by to achieve nutritional goals $(\mathrm{n}=40,20.5 \%)$, increase performance in sports $(n=35,17.9 \%)$, obtain energy $(n=31$, $15.9 \%)$, gain weight $(\mathrm{n}=29,14.9 \%)$, and to enhance memory $(n=21,10.8 \%)$. Furthermore, detailed responses are shown in Figure 3. There were significant differences between faculty type and statements about whether "dietary supplements are good for health" $(\mathrm{p}=0.001)$, residential status $(\mathrm{p}=0.125)$, and suffering from illness $(\mathrm{p}=$ 0.175). Furthermore, there were significant associations
Table 2 The Frequency of the Use of Dietary Supplements

\begin{tabular}{|l|l|}
\hline Variables & N (\%) \\
\hline Do you use any dietary supplements? & $43(22.1)$ \\
\hline Daily & $27(13.9)$ \\
Weekly & 21 (10.8) \\
Monthly & $85(43.8)$ \\
Never & $18(9.2)$ \\
Am not sure if I have used dietary supplements in the last \\
3 months & \\
\hline Which type of dietary supplements do you use? \\
\hline Generic (local) & $20(9.7)$ \\
Branded (imported internationally) & $37(19)$ \\
Both & $24(12.3)$ \\
I do not know & $30(15.4)$ \\
I do not use dietary supplements & $85(43.8)$ \\
\hline
\end{tabular}

Have you experienced any side effects related to your dietary supplement use?

Yes, I suffered from side effects

$16(8.2)$

I suffered from side effects but am not sure whether they

were related to dietary supplement use

No, I did not suffer from any adverse events $8(4.2)$

Not applicable because I did not use any dietary

supplements

If you suffered from side effects related to dietary supplement use, please indicate the type of side effects:

Adverse effects related to nausea, vomiting, diarrhea

II (5.6)

Side effects related to headache, confusion, and

$5(2.6)$

disorientation

I did not suffer from any side effects

$73(37.4)$

I did not use dietary supplements (Not applicable)

Other

Most commonly used dietary supplements

Multivitamins (mixture of A-Z)

$22(11.3)$

Ginseng

$22($ (II.3)

Gingko biloba

Glucosamine/omega 3 fatty acids

$9(4.6)$

Whey proteins

$32(16.4)$

Evening primrose oil

$37(19)$

Fibers

$5(2.6)$

$48(24.6)$

Abbreviations: $\mathrm{N}$, number; \%, percentile.

between opinions on DSs and faculty type $(p=0.004)$ and suffering from illness $(p=0.345)$. However, there was no statistically significant difference in opinions regarding DSs between students who lived with or without family ( $\mathrm{p}$ $=0.994)$. Similarly, there was no significant association between encouragement regarding the use of DSs and residential status $(\mathrm{p}=0.533)$ (Table 4$)$. 
Table 3 Participants' Attitudes Regarding Dietary Supplements

\begin{tabular}{|c|c|}
\hline & $\mathbf{N}(\%)$ \\
\hline \multicolumn{2}{|c|}{ Are dietary supplements good for health? } \\
\hline Yes & $169(86.7)$ \\
\hline I do not know & $20(10.3)$ \\
\hline No & $5(2.6)$ \\
\hline \multicolumn{2}{|c|}{ Do you encourage the use of dietary supplements? } \\
\hline Yes, I always encourage them to use & $71(36.4)$ \\
\hline Yes, only on doctors recommendation & $101(5 \mid .8)$ \\
\hline Not at all & $22(11.3)$ \\
\hline
\end{tabular}

Abbreviations: $\mathrm{N}$, number; \%, percentile.

\section{Discussion}

The present findings indicated that $46.8 \%$ of the participants were using DSs, which was lower than that in previous studies conducted among a sample of pharmacy students by Naqvi et al (48.2\%), ${ }^{39}$ among health science students $(53.6 \%)$ by Alowais and Selim, ${ }^{18}$ and in a study by Aljaloud and Ibrahim among professional athletes in Saudi Arabia (93.3\%). ${ }^{27}$ However, these results were higher than studies published by Žeželj et al among medical and nonmedical students in the University of Rijeka, Croatia $^{40}$ and by Kobayashi et al among Japanese students, ${ }^{24}$ who reported that $30.5 \%$ and $16.8 \%$ of students used DSs, respectively. Additionally, these results were lower than those reported in studies by Jairoun et al among Emirati athletes ${ }^{17}$ and by Al-Johani et al among Saudi medical students. ${ }^{16}$ Furthermore, the findings of our study are lower than previous studies conducted among British pharmacy students, ${ }^{7}$ Nigerian students, ${ }^{23}$ and Saudi female students. ${ }^{15}$ Thus, the literature confirmed that the use of DSs is common among university students both in Saudi Arabia and worldwide. ${ }^{41}$ This relatively high prevalence of DS consumption may occur because beliefs about the need for supplement use are widespread.

The prevalence of DS use may differ from one study to another and may be influenced by several factors including the study method, types of respondents, and demographics of the subjects. However, in many developed and developing countries, ${ }^{42,43}$ supplement usage is increasing and is reported to be a common practice. ${ }^{44-47}$ Studies around the world have reported that many pharmacists do not strictly adhere to the health-care laws when prescribing DSs, although the results also revealed overprescribing in Saudi Arabia. ${ }^{44,45}$ Additionally, studies found that irrational prescribing is the most common practice in Arab countries and other developing countries, which may be responsible for the relatively high use of DSs in this study.

The most common justification among the students in this study to indulge in the use of DSs was to maintain general health and wellbeing, followed by overcoming nutritional deficits to increase performance in sports, gain weight, and increase immunity. Similar results were reported by Axon et al, 2017, who reported that DSs were used for disease prevention (24\%), physical improvement $(19 \%)$, to recover or improve immunity $(16 \%)$, to improve sports performance $(9 \%)$, to improve mental

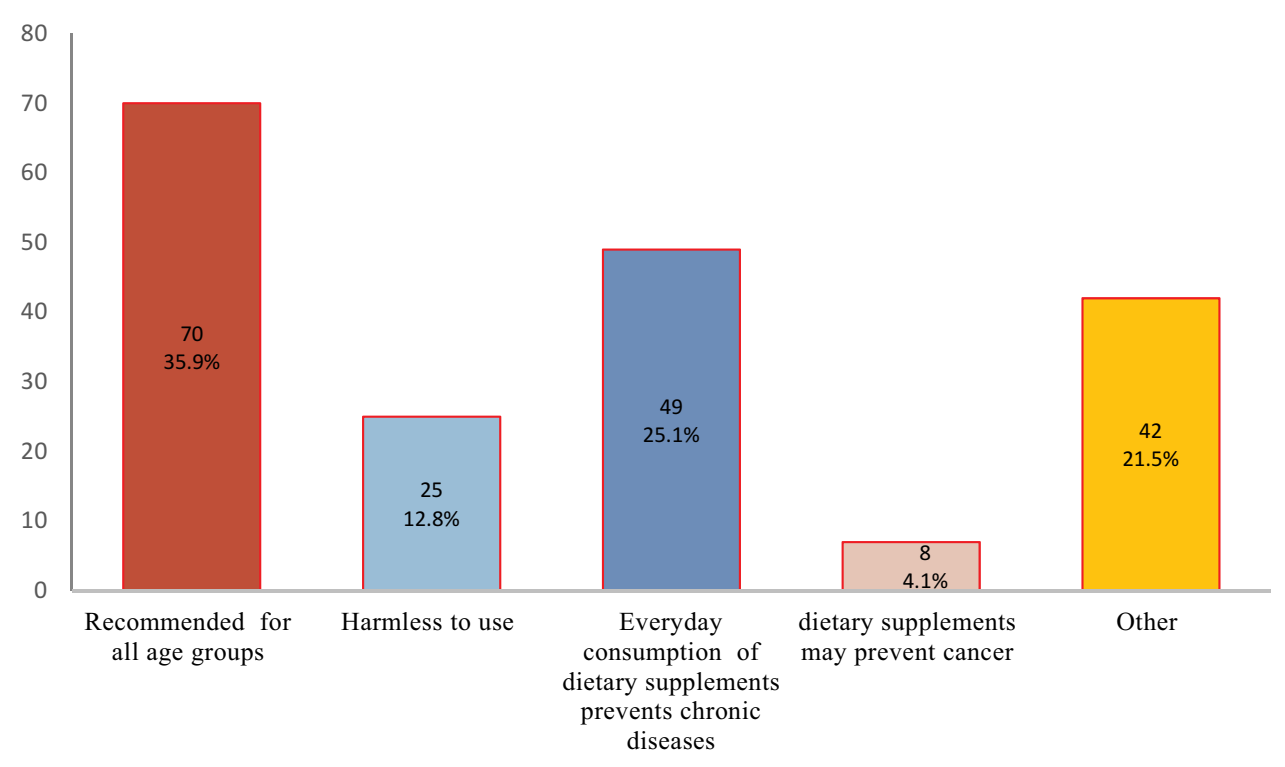

Figure 2 Student views toward the use of dietary supplements $(n=194)$. 


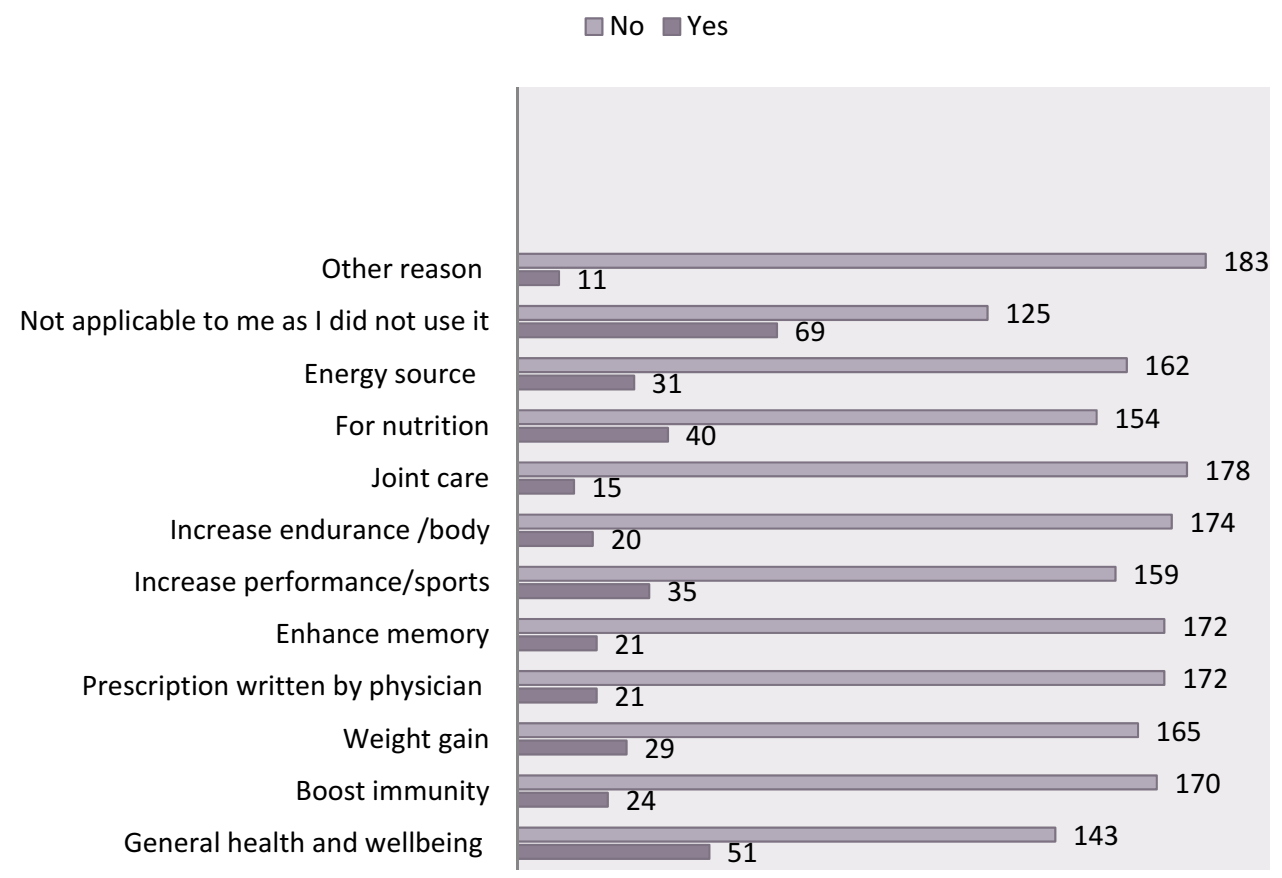

Figure 3 Reasons for taking dietary supplements.

ability or memory $(8 \%)$, and to improve sexual performance (1\%). ${ }^{7}$ Another study by Alhomoud FK 2016 on Health Sciences and Non-Health Sciences students from the University of United Arab Emirates reported justifications for the use of DSs included maintain good health $(21 \%)$ and ensuring adequate nutrition (15\%). Additionally, previous findings have reported a higher prevalence of DS use in female in than male students. ${ }^{41,45}$ Unfortunately, our results were limited to only male students because of the Islamic culture of Saudi Arabia, which prohibits the gathering of both males and females in one place. This is the main justification for excluding females from this study.

Most of the students in this study reported that DSs are good for health. Additionally, the students also believed that the everyday use of DSs prevents chronic diseases. Slightly more than half of the respondents reported that they encouraged the use of DSs. Conversely, a previous study by Axon DR who measured the attitudes of pharmacy students toward DSs reported that they believed DSs were not essential for health and wellbeing. ${ }^{7,47}$ This variation in the findings might be due to eating habits, prescribing patterns, or health-care regulations in the country.

The findings of the present study differed from those of previous studies conducted among practicing pharmacists rather than student pharmacists. A previous study reported that a balanced diet is better achieved by eating healthy food rather than taking supplements; additionally, most community pharmacists reported that the use of DSs may be toxic, DSs may include some unlabeled harmful ingredients, and that antioxidants and vitamins have an unproven value and may cause chronic diseases. ${ }^{48}$ This difference might be due to the nature of the pharmacist assessed; specifically, practicing pharmacists are more knowledgeable than student pharmacists.

Among the DS users in this current study, most used DSs for fibers, whey proteins, omega 3 fatty acids, and multivitamins. These study findings were consistent with those of two previous studies ${ }^{7,46}$ conducted in developed countries in which multivitamins (91\%), vitamin C (71\%), fish oil (65\%), probiotics $(53 \%)$, and fiber $(53 \%)$ were the most common products among users. ${ }^{45}$ However, another study among British pharmacy students in 2017 reported that glucosamine/chondroitin, fiber/psyllium, Echinacea, Tiger balm, and omega-3/fish oil was the most common DSs. ${ }^{7}$ A study by Naqvi et al 2019 reported that $51.5 \%$ of pharmacy students used multivitamins. ${ }^{39}$ This increasing rate of DS consumption suggests the need to establish criteria for irrational prescriptions of DSs in health-system formularies should be as mandatory requirement as those established for nonprescription drugs. Additionally, determining by oneself to use DSs may increase the patients' risk of developing an adverse reaction. Therefore, an awareness of the usage of DSs should be integrated into everyday practice. One of the 
Table 4 The Association Between Demographics and Some Variables

\begin{tabular}{|c|c|c|c|c|c|c|c|c|c|}
\hline \multirow[t]{2}{*}{ Questionnaire } & \multicolumn{3}{|c|}{ Faculty Type } & \multicolumn{3}{|c|}{ Residential Status } & \multicolumn{3}{|c|}{ Suffering from Illness } \\
\hline & $\begin{array}{l}\text { BPhar } \\
\text { n (\%) }\end{array}$ & $\begin{array}{l}\text { PharD } \\
\text { n (\%) }\end{array}$ & P-value & $\begin{array}{l}\text { With } \\
\text { Family } \\
\text { n (\%) }\end{array}$ & $\begin{array}{l}\text { Without } \\
\text { Family n (\%) }\end{array}$ & P value & $\begin{array}{l}\text { Yes } \\
\text { n (\%) }\end{array}$ & No $n(\%)$ & $P$ value \\
\hline \multicolumn{10}{|c|}{ Dietary supplements are good for health? } \\
\hline $\begin{array}{l}\text { Yes } \\
\text { I do not know } \\
\text { No }\end{array}$ & $\begin{array}{l}67(77.9) \\
14(16.3) \\
5(5.8)\end{array}$ & $\begin{array}{l}102(94 .) \\
6(5.6) \\
0\end{array}$ & 0.001 & $\begin{array}{l}15 \mid(88 .) \\
17(9.9) \\
3(1.8)\end{array}$ & $\begin{array}{l}18(78.3) \\
3(13) \\
2(8.7)\end{array}$ & 0.12 & $\begin{array}{l}20(100) \\
- \\
-\end{array}$ & $\begin{array}{l}149(85.6) \\
20(11.5) \\
5(2.9)\end{array}$ & 0.17 \\
\hline \multicolumn{10}{|c|}{ Your opinion about dietary supplements? } \\
\hline $\begin{array}{l}\text { I. Necessary for all ages } \\
\text { 2. They are harmless } \\
\text { 3. Regular use may prevent } \\
\text { chronic diseases } \\
\text { 4. May prevent cancer } \\
\text { 5. Other }\end{array}$ & $\begin{array}{l}23(26.7) \\
15(17.4) \\
18(20.9) \\
6(7) \\
24(27.9)\end{array}$ & $\begin{array}{l}47(43.9) \\
10(9.3) \\
31(29) \\
1(0.9) \\
18(16.8)\end{array}$ & 0.004 & $\begin{array}{l}61(35.9) \\
22(12.9) \\
44(25.9) \\
6(3.5) \\
37(21.8)\end{array}$ & $\begin{array}{l}9(39.1) \\
3(13) \\
5(21.7) \\
1(4.3) \\
5(21.7)\end{array}$ & 0.99 & $\begin{array}{l}8(40) \\
5(25) \\
3(15) \\
0 \\
4(20)\end{array}$ & $\begin{array}{l}62(35.8) \\
20(11.6) \\
46(26.6) \\
7(4) \\
38(22)\end{array}$ & 0.34 \\
\hline \multicolumn{10}{|c|}{ Do you encourage the use of dietary supplements? } \\
\hline $\begin{array}{l}\text { I. Yes, I always recommend } \\
\text { them } \\
\text { 2. Yes, only on doctors } \\
\text { recommendation } \\
\text { 3. Do not recommend at all }\end{array}$ & $\begin{array}{l}29(33.7) \\
44(51.2) \\
13(15.1)\end{array}$ & $\begin{array}{l}42(38.9) \\
57(52.8) \\
9(8.3)\end{array}$ & 0.312 & $\begin{array}{l}62(36.3) \\
91(53.2) \\
18(10.5)\end{array}$ & $\begin{array}{l}9(39.1) \\
10(43.5) \\
4(17.4)\end{array}$ & 0.533 & $\begin{array}{l}6(30) \\
13(65) \\
1(5)\end{array}$ & $\begin{array}{l}65(37.4) \\
88(50.6) \\
21(12.1)\end{array}$ & 0.392 \\
\hline
\end{tabular}

Notes: $P<0.5=$ significant; $P>0.5=$ insignificant.

strengths of this study was that students reported positive opinions and views toward the use of DSs. This indicates a good level of knowledge about the rational use of performance boosters, which they may have gained from the current curriculum. Health-care students are more knowledgeable about such topics than non-health-care students and other populations. ${ }^{39,41}$ This study has some limitations. Firstly, this study used a cross-sectional design and therefore only provides a snapshot of the participants' use and opinions relating to DSs at the time of the survey. Secondly, the study population was limited to male students due to gender restrictions in Saudi Arabia. Thirdly, this study used a convinced sampling method and considered only students who were present in class during the time the questionnaire was administered. Finally, this study only examined pharmacy students from one college of pharmacy; thus, the results may not be generalizable to all pharmacy students across Saudi Arabia or the general population.

\section{Conclusions}

Our study highlights the increasing trend of DS use among Saudi students living in the capital of Saudi Arabia, Riyadh city. More importantly, the prevalence of DS use was on the rise compared with both national and international studies, which potentially predicts an increase in negative consequences. The present results could serve as support for faculties of pharmacy to improve their curriculum to encourage better and safer use of DSs and to support the development of messages aimed to safely use DSs. Therefore, we advocate the implementation of educational programs that teach students how to use DSs to avoid their complications and achieve the optimum therapeutic benefits.

\section{Acknowledgments}

The authors extend their appreciation to the Deanship of Scientific Research at King Saud University for funding the work through the research group project No. RG-1441073. In addition, the authors thank the Deanship of Scientific Research and RSSU at King Saud University for their technical support.

\section{Author Contributions}

All authors of this study made substantial contributions to the conception and design, acquisition, or analysis of 
research data and data interpretation; took part in drafting the article or revising it critically for important intellectual content; gave final approval of the version to be published; and agree to be accountable for all aspects of the work.

\section{Funding}

This research was funded by DSR (Deanship of Scientific Research) at King Saud University through the research group project No. (RG-1441-073).

\section{Disclosure}

The authors declare no conflicts of interest in this work.

\section{References}

1. Greger JL. Dietary supplement use: consumer characteristics and interests. J Nutr. 2001;131(4)(suppl):1339S-1343S. doi:10.1093/jn/ 131.4.1339S

2. Marcus DM. Dietary supplements: what's in a name? What's in the bottle? Drug Test Anal. 2016;8(3-4):410-412. doi:10.1002/dta.1855

3. United States Food and Drug Administration (FDA). What is a dietary supplement? Available from: http://www.fda.gov/aboutfda/ transparency/basics/ucm195635.htm. Accessed January 18, 2016.

4. Barnes PM, Powell-Griner E, McFann K, Nahin RL. Complementary and alternative medicine use among adults: United States, 2002. $A d v$ Data. 2004;27(343):1-19.

5. Chauhan B, Kumar G, Kalam N, Ansari SH. Current concepts and prospects of herbal nutraceutical: a review. J Adv Pharm Technol Res. 2013;4(1):4-8. doi:10.4103/2231-4040.107494

6. Kennedy J. Herb and supplement use in the US adult population. Clin Ther. 2005;27(11):1847-1858. doi:10.1016/j.clinthera.2005.11.004

7. Axon DR, Vanova J, Edel C, Slack M. Dietary supplement use, knowledge, and perceptions among student pharmacists. $A m$ J Pharm Educ. 2017;81(5):92. doi:10.5688/ajpe81592

8. Kennedy ET, Luo H, Houser RF. Dietary supplement use pattern of U.S. adult population in the 2007-2008 National Health and Nutrition Examination Survey (NHANES). Ecol Food Nutr. 2013;52(1):76-84. doi:10.1080/03670244.2012.706000

9. Satia-Abouta J, Kristal AR, Patterson RE, Littman AJ, Stratton KL, White E. Dietary supplement use and medical conditions: the VITAL study. Am J Prev Med. 2003;24(1):43-51. doi:10.1016/S07493797(02)00571-8

10. Evans MW, Ndetan H, Perko M, Williams R, Walker C. Dietary supplement use by children and adolescents in the United States to enhance sport performance: results of the National Health Interview Survey. J Prim Prev. 2012;33(1):3-12. doi:10.1007/s10935-0120261-4

11. Wu CH, Wang CC, Kennedy J. The prevalence of herb and dietary supplement use among children and adolescents in the United States: results from the 2007 national health interview survey. Complement Ther Med. 2013;21(4):358-363. doi:10.1016/j.ctim.2013.05.001

12. Wilson KM, Klein JD, Sesselberg TS, et al. Use of complementary medicine and dietary supplements among U.S. adolescents. $J$ Adolesc Health. 2006;38(4):385-394. doi:10.1016/j.jadohealth.2005.01.010

13. Diehl K, Thiel A, Zipfel S, Mayer J, Schnell A, Schneider S. Elite adolescent athletes' use of dietary supplements: characteristics, opinions, and sources of supply and information. Int J Sport Nutr Exerc Metab. 2012;22(3):165-174. doi:10.1123/ijsnem.22.3.165

14. AlTamimi JZ. Awareness of the consumption of dietary supplements among students in a University in Saudi Arabia. J Nutr Metab. 2019;2019:4641768. doi:10.1155/2019/4641768
15. Alfawaz H, Khan N, Alfaifi A, et al. Prevalence of dietary supplement use and associated factors among female college students in Saudi Arabia. BMC Women's Health. 2017;17(1):116. doi:10.1186/ s12905-017-0475-y

16. Al-Johani WM, Al-Dawood KM, Abdel Wahab MM, Yousef HA. Consumption of vitamin and mineral supplements and its correlates among medical students in Eastern Province, Saudi Arabia. J Family Community Med. 2018;25(3):169-174.

17. Jairoun AA, Al-Hemyari SS, Shahwan M, et al. What are the beliefs and behaviours related to sport nutrition supplements, particularly regarding UAE regulatory issues, among male fitness centre members in Dubai? Clin Epidemiol Glob Health. 2020;8(3):934-938. doi:10.1016/j.cegh.2020.02.027

18. Alowais MA, Selim MAE. Knowledge, attitude, and practices regarding dietary supplements in Saudi Arabia. J Family Med Prim. 2019;8 (2):365-372. doi:10.4103/jfmpc.jfmpc_430_18

19. Naqvi AA, Ahmad R, Elewi AAW, AlAwa AH, Alasiri MJ. Dietary supplement use among undergraduate male students in health and non-health cluster colleges of a public-sector university in Dammam, Saudi Arabia. BMC Complement Altern Med. 2018;18(1):269. doi:10.1186/s12906-018-2332-4

20. Lieberman HR, Marriott BP, Williams C, et al. Patterns of dietary supplement use among college students. Clin Nutr. 2015;34 (5):976-985. doi:10.1016/j.clnu.2014.10.010

21. Radwan H, Hasan HA, Ghanem L, et al. Prevalence of dietary supplement use and associated factors among college students in the United Arab Emirates. J Commun Health. 2019;44(6):11 35-1140. doi:10.1007/s10900-019-00700-2

22. CRN. The science behind the supplements; dietary supplement usage increases, says new survey; 2017. Available from: https://www. crnusa.org/newsroom/dietary-supplement-usage-increases-says-newsurvey. Accessed August 20, 2020.

23. Aina BA, Ojedokun OA. Knowledge and use of dietary supplements by students of college of medicine. Lagos: University of Lagos, Idi-Araba, Lagos, Nigeria. J Bas Clinic Pharm. 2014;5(2):34-39. doi:10.4103/0976-0105.134952

24. Kobayashi E, Sato Y, Umegaki K, Chiba T. The prevalence of dietary supplement use among college students: a nationwide survey in Japan. Nutrients. 2017;9(11):1250. doi:10.3390/nu9111250

25. GCC pharmaceutical industry report 2013. Dubai, United Arab Emirates: alpen. Capital; 2013. Available from: http://www.alpenca pital.\%20com/media-reports-2013.htm. Accessed July 18, 2014.

26. Muttappallymyalil J, Sreedharan J, John J, et al. Self-reported use of complementary and alternative medicine among the health care consumers at a tertiary care center in Ajman, United Arab Emirates. Ann Med Health Sci Res. 2013;3(2):215-219. doi:10.4103/2141-9248.113 665

27. Aljaloud SO, Ibrahim SA. Use of dietary supplements among professional athletes in Saudi Arabia. J Nutr Metab. 2013;2013:245349. doi:10.1155/2013/245349

28. Al SI, Ismail MF, Yousuf WA, Salama RE. Knowledge, attitudes and practice of general practitioners towards complementary and alternative medicine in Doha, Qatar. East Mediterr Health J. 2010;16 (5):522-527. doi:10.26719/2010.16.5.522

29. Radimer K, Bindewald B, Hughes J, Ervin B, Swanson C, Picciano MF. Dietary supplement use by US adults: data from the National Health and nutrition examination survey, 1999-2000. Am J Epidemiol. 2004;160(4):339-349. doi:10.1093/aje/kwh207

30. Rock CL. Multivitamin-multimineral supplements: who uses them? Am J Clin Nutr. 2007;85(1):277S-279S. doi:10.1093/ajen/85.1.277S

31. Kim SH, Han JH, Keen CL. Vitamin and mineral supplement use by healthy teenagers in Korea: motivating factors and dietary consequences. Nutrition. 2001;17(5):373-380. doi:10.1016/S0899-9007(00)00582-7

32. Suleiman AA, Alboqai OK, Yasein N, Al-Essa MK, El Masri K. Prevalence of vitamin-mineral supplement use among Jordan University students. Saudi Med J. 2008;29(9):1326-1331. 
33. Braun M, Venter I. Use of dietary supplements, and awareness and knowledge of the recommended fruit and vegetable intakes and consumption of health food store customers in the Cape Town city bowl. South Afr J Clin Nutr. 2008;21(4):323-330. doi:10.1080/ 16070658.2008.11734174

34. Chiba T, Sato Y, Suzuki S, Umegaki K. Concomitant use of dietary supplements and medicines in patients due to miscommunication with physicians in Japan. Nutrients. 2015;7(4):2947-2960. doi:10.33 90/nu7042947

35. Timbo BB, Ross MP, McCarthy PV, Lin CT. Dietary supplements in a national survey: prevalence of use and reports of adverse events. $J$ Am Diet Assoc. 2006;106(12):1966-1974. doi:10.1016/j.jada.2006. 09.002

36. Chyka PA, McCommon SW. Reporting of adverse drug reactions by poison control centres in the US. Drug Saf. 2000;23(1):87-93. doi:10.2165/00002018-200023010-00006

37. Etikan I, Musa SA, Alkassim RS. Comparison of convenience sampling and purposive sampling. J Theor Appl Stat. 2016;5(1):1-4. doi:10.11648/j.ajtas.20160501.11

38. Osborne JW. Best Practices in Data Cleaning: A Complete Guide to Everything You Need to Do Before and After Collecting Your Data. Sage; 2013. doi:10.4135/9781452269948

39. Naqvi AA, Ahmad R, Zehra F, Yousuf R, Kachela B, Nehal Nadir M. Dietary supplement use among students of pharmacy colleges in the City of Karachi, Pakistan: prevalence, opinions, and attitudes. J Diet Suppl. 2019;16(2):166-178. doi:10.1080/19390211.2018.1443191

40. Žeželj SP, Tomljanović A, Jovanović GK, et al. Prevalence, knowledge and attitudes concerning dietary supplements among a student population in Croatia. Int J Environ Res Public Health. 2018;15(6): E1058. doi:10.3390/ijerph15061058
41. Alhomoud FK, Basil M, Bondarev A. Knowledge, attitudes and practices (KAP) relating to dietary supplements among health sciences and non-health sciences students in one of the universities of United Arab Emirates (UAE). J Clin Diagn Res. 2016;10(9):JC05JC09. doi:10.7860/JCDR/2016/19300.8439

42. Al-Worafi YM. Pharmacy practice and its challenges in Yemen. Australas Med J. 2014;7(1):17-23. doi:10.4066/AMJ.2014.1890

43. Fathelrahman AI, Ibrahim MIM, Wertheimer A. 2016. Pharmacy Practice in Developing Countries: Achievements and Challenges. Cambridge: Academic Press. ISBN 978-0-12-801714-2.

44. Wajid S, Al-Arifi MN, Al Nomay HA, Al Mousa YN, Babelghaith SD. Knowledge and perception of community pharmacists towards generic medicines in Saudi Arabia. Biomed Res. 2015;26(4):800-806.

45. Al-Mohamadi A, Badr A, Bin Mahfouz LB, Samargandi D, Al Ahdal A. Dispensing medications without prescription at Saudi community pharmacy: extent and perception. Saudi Pharm J. 2013;21 (1):13-18. doi:10.1016/j.jsps.2011.11.003

46. Marupuru S, Axon DR, Slack MK. How do pharmacists use and recommend vitamins, minerals, herbals and other dietary supplements? BMC Complement Altern Med. 2019;19(1):229. doi:10.1186/s12906-019-2637-y

47. Edel C, Vanova J, Slack M. Use of dietary supplements among pharmacy students; 2015. Avaiable from: https://repository.arizona. edu/handle/10150/614106. Accessed August 20, 2020.

48. Shilbayeh SA. Exploring knowledge and attitudes towards counselling about vitamin supplements in Jordanian community pharmacies. Pharm Pract (Granada). 2011;9(4):242-251. doi:10.4321/S188636552011000400010
Risk Management and Healthcare Policy

\section{Publish your work in this journal}

Risk Management and Healthcare Policy is an international, peerreviewed, open access journal focusing on all aspects of public health, policy, and preventative measures to promote good health and improve morbidity and mortality in the population. The journa welcomes submitted papers covering original research, basic science, clinical \& epidemiological studies, reviews and evaluations, guidelines, expert opinion and commentary, case reports and extended reports. The manuscript management system is completely online and includes a very quick and fair peer-review system, which is all easy to use. Visit http://www.dovepress.com/testimonials.php to read real quotes from published authors. 